Division of Geological \& Geophysical Surveys

RAW-DATA FILE 2013-4

MERCURY INJECTION CAPILLARY PRESSURE RESULTS FROM OUTCROP SAMPLES IN THE TYONEK, BELUGA, AND WEST FORELAND FORMATION, TYONEK AND TALKEETNA QUADRANGLES

by

Andrea M. Loveland and PetroTech Associates

$\$ 2.00$

JULY 2013

THIS REPORT HAS NOT BEEN REVIEWED FOR TECHNICAL CONTENT OR FOR CONFORMITY TO THE EDITORIAL STANDARDS OF DGGS

Released by

STATE OF ALASKA

DEPARTMENT OF NATURAL RESOURCES

Division of Geological \& Geophysical Surveys

3354 College Road

Fairbanks, Alaska 99709-3707 



\title{
MERCURY INJECTION CAPILLARY PRESSURE RESULTS FROM OUTCROP SAMPLES IN THE TYONEK, BELUGA, AND WEST FORELAND FORMATIONS, TYONEK AND TALKEETNA QUADRANGLES
}

\author{
by
}

Andrea M. Loveland ${ }^{1}$ and PetroTech Associates ${ }^{2}$

${ }^{1}$ Division of Geological \& Geophysical Surveys, 3354 College Road, Fairbanks, Alaska 99709-3707; andrea.loveland@alaska.gov

${ }^{2}$ PetroTech Associates, 11767 Katy Freeway, Suite 320, Houston, Texas 77079

\section{INTRODUCTION}

This report summarizes mercury injection capillary pressure (MICP) data for 38 outcrop samples collected from the Tyonek, Beluga, and West Foreland Formations in the Tyonek and Talkeetna quadrangles (fig. 1). All samples were collected from measured stratigraphic sections. Measured section sample coordinates represent the location of the bottom of the stratigraphic measured section. All samples were analyzed by PetroTech Associates, Houston, TX.

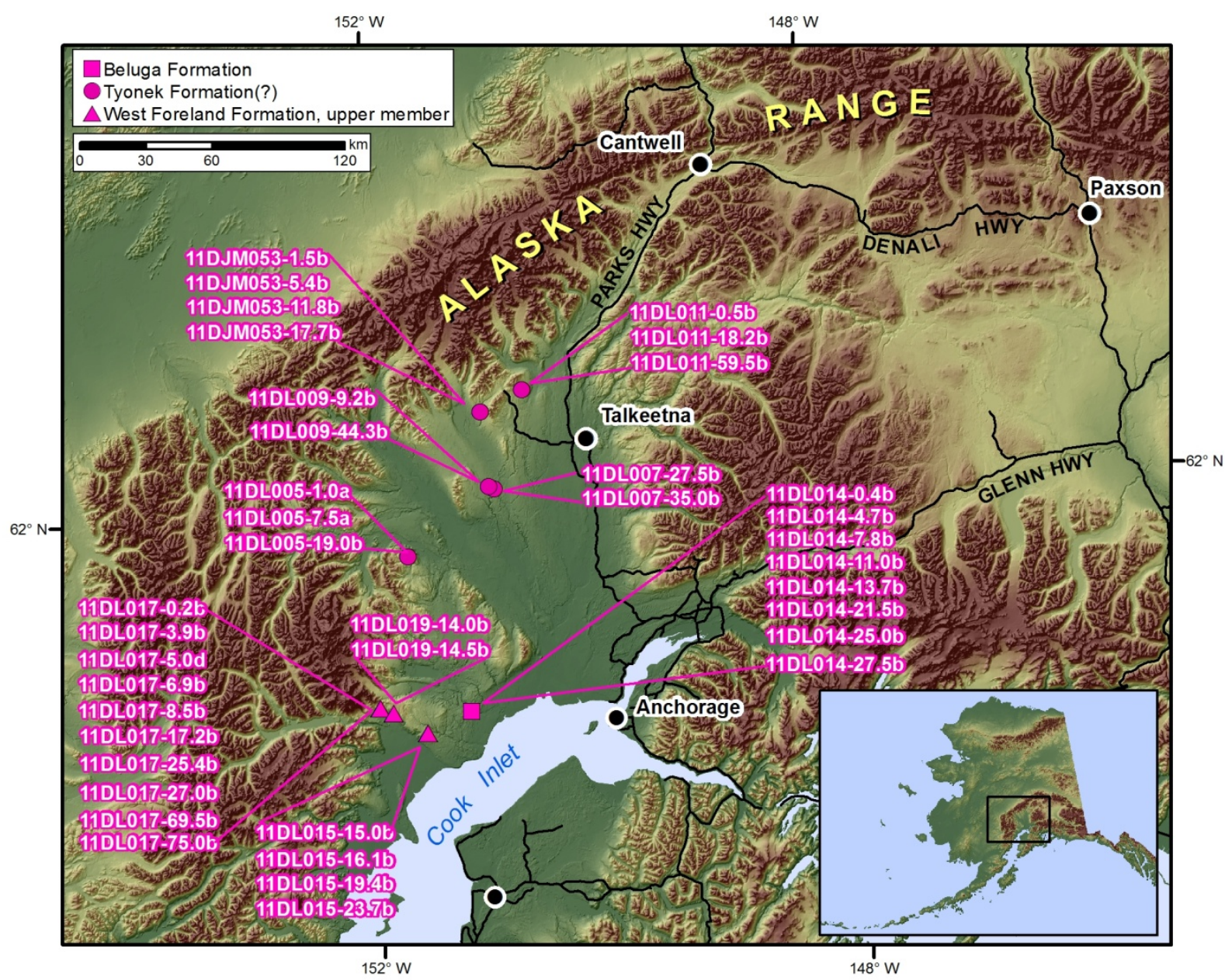

Figure 1. Map showing the locations from which 38 outcrop samples were collected for MICP analysis in the Beluga, Tyonek, and West Foreland Formations. 


\section{DATA FILES}

The data for this publication is provided in its native spreadsheet format. The citation index page for this publication is (http://dggs.alaska.gov/pubs/id/25299). The digital dataset includes:

- Sample names, coordinates, and the formation from which samples were collected

- Per/sample pore aperture size distribution charts

- Formation pore volume graphs and data

- Pore system properties of the Tyonek, Beluga, and West Foreland Formations

A detailed description of the digital data files can be found in the associated metadata file.

The following pages include correspondence from PetroTech Associates describing the methods used in MICP analyses of the samples in this report, a brief summary of the data, and references cited. 


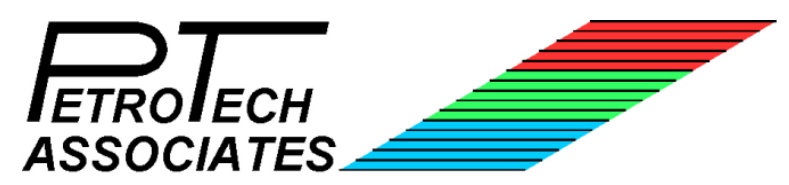

11767 Katy Freeway, Suite 320

Houston, Texas 77079

Tel: 281.558.3996 Fax: 281.558.3998

March 1, 2012

David L. LePain

Alaska Division of Geological \& Geophysical Surveys

3354 College Road

Fairbanks, AK 99709

Dear Dave,

PetroTech has completed high-pressure mercury injection capillary pressure analysis of thirtyeight (38) outcrop samples from the Susitna and Tyonek areas. Sample designations, formations and location information are provided in Table 1. For the tables and figures in the report, the samples are separated into three groups: 1) the Tyonek Formation, Tyonek and Talkeetna Quadrangles, 2) Beluga Formation, Tyonek Quadrangle and 3) West Foreland Formation, upper member, Tyonek Quadrangle.

Following receipt of the samples, a representative portion of each was trimmed to fit the sample holders and examined under reflected light microscopy to note any irregularities that might affect the data quality. The rock surfaces were cleaned of any mud or dust and the samples then dried to a constant weight in a low temperature oven before being analyzed.

During capillary pressure testing, the volume of mercury injected was measured at 118 pressure points from 1.64 to 59,500 psia. These data were then corrected for closure. The "closure" volume is the amount of mercury intrusion that occurs as the mercury conforms to the sample surface, filling any irregularities, prior to entering the pore system. A table of the data and separate plots of cumulative bulk volume and wetting phase saturation versus capillary pressure, as well as the incremental pore aperture size distribution, are included for each sample. Composite plots of the drainage data (Figure 1) and pore aperture size distributions (Figure 2) are provided as an aid when comparing samples.

Table 1 contains the porosity and permeability values derived from the capillary pressure testing. The porosity is based on an Archimedes bulk volume and the closure corrected volume of mercury injected during testing (pore volume). The permeability is estimated using the Swanson equation (SPE, 1981) and the values of cumulative bulk volume and capillary pressure at maximum intrusion. The porosity ranges from $10.38 \%$ to $40.89 \%$; however, a majority of the samples (24 of the 38 ) have porosity between $20 \%$ and $30 \%$. The remaining samples are equally divided between those having $<20 \%$ and those having $>30 \%$ porosity. There is a wide range in permeability, which varies from $0.00062 \mathrm{md}$ to $530 \mathrm{md}$. Slightly more 
than $50 \%$ of the samples have permeability between $0.1 \mathrm{md}$ and $2 \mathrm{md}$. There is no obvious relationship between porosity and permeability.

The capillary pressure data is displayed by formation in Figures 1 and 2, and information on the pore system properties is also contained in Table 2. The Tyonek Formation samples have unimodal pore systems. A majority have well defined to sharp intrusion profiles with peaks located at apertures between 0.1 and 0.7 microns diameter. Three samples (005-1.0a, 00727.5b, 011-59.5b) have more heterogeneous pore systems (broader intrusion profiles). The median aperture size for these samples is 0.2688 microns. Two Tyonek samples (011-0.5b, 011-18.2b) are sandstones with large diameter intergranular pores. Peak intrusion for these rocks occurs through apertures of 16.5 and 33.8 microns, respectively, and median aperture size is in the $9-12$ micron range.

The Beluga Formation samples are characterized by unimodal pore systems and relatively broad intrusion profiles reflecting more heterogeneity. Maximum intrusion occurs at pore apertures between 0.1 and 0.6 microns and the median aperture size is 0.1757 microns. The exception is sample 014-13.7b which has a better defined profile and, peak and median aperture sizes below 0.1 micron.

The West Foreland Formation samples have much more heterogeneous pore structures and a majority of the samples display some level of bimodality. Two samples appear trimodal. The peaks are not well defined and the initial peak is commonly the more dominant. That is, it controls access to more of the pore volume. Peak locations vary, with the initial peak generally above 1 micron aperture size and the second peak below 0.1 micron, often $<0.01$ micron. The larger pore apertures associated with the initial peaks support higher permeability, with most samples above $1 \mathrm{md}$. Two samples (017-0.2b, 017-17.2b) have unimodal profiles and intrusion peaks at 0.016 and 0.005 microns.

The air/mercury capillary entry pressures are less than 300 psia for a majority of the samples. The West Foreland Formation samples and the sandstone samples from the Tyonek Formation have entry pressures less than 100 psia.

Six samples from within the various formations have entry pressures above 500 psia and these were evaluated for potential seal capacity. The air/mercury capillary pressure data were converted to gas/water and oil/water systems assuming a gas/water surface tension of 50 dynes/cm and an oil/water interfacial tension of $30 \mathrm{dynes} / \mathrm{cm}$. Subsequent conversion to equivalent height was made using the following values (reservoir conditions):

\begin{tabular}{|c|c|c|}
\hline Water Density & Gas Density & Oil Density \\
\hline $1.016 \mathrm{~g} / \mathrm{cc}$ & $0.28 \mathrm{~g} / \mathrm{cc}$ & $0.69 \mathrm{~g} / \mathrm{cc}$ \\
\hline
\end{tabular}

Calculations of potential seal capacity (hydrocarbon column held) were made for hydrocarbon saturations in the seal of $0 \%$ (entry), $5 \%, 7.5 \%$ and $10 \%$ and are plotted in Figures 3 and 4. The value at a saturation of $7.5 \%$ is often used to indicate the point where the hydrocarbon phase in the seal rock is continuous enough to cause the seal to leak and these values are displayed separately in Figures 5 and 6 . A file is included that contains the calculations used to convert the air/mercury capillary pressure to height. The fluid properties (densities and surface tensions) used to derive these column heights can be changed in the spreadsheet and the potential seal capacities will be re-calculated and the new values plotted. 
Data for the potential seal rocks is contained in Table 3. Three of the samples are Type C seals, under the Sneider Classification, and have an average potential seal capacity for oil of 565 feet, and 417 feet for gas (assuming 7.5\% hydrocarbon saturation in the seal). One sample from the Beluga Formation is a Type $B$ seal capable of trapping 2,670 feet and 1,971 feet of oil and gas, respectively. The best seals (Type $A$ and $A^{*}$ ) are from the West Foreland Formation, upper member, and have much higher potential seal capacities, up to 7,132 feet of oil and 5,265 feet of gas for the Type $A^{*}$ seal.

PetroTech has assigned project code PA - 1163 to this study. We appreciate the opportunity to provide these services. Please contact us with any comments or questions regarding the data or analytical procedures.

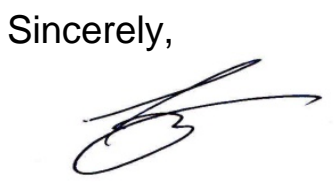

George Bolger

References cited

Sneider, R.M., 1991, Petrophysical properties of seals, in Seals, Traps and the Petroleum System, AAPG Memoir 67; R.C. Surdam (Ed.); American Association of Petroleum Geologists, Tulsa, OK, 317 p.

Swanson, B.F., 1981, A simple correlation between permeabilities and mercury capillary pressures, Journal of Petroleum Technology, pp 2498-2504. 